\title{
A ATUAÇÃO DO ADMINISTRADOR NO CUMPRIMENTO DA FUNÇÃO SOCIAL DIANTE DO CÓDIGO DE DEFESA DO CONSUMIDOR.
}

\author{
Alessandra Harumi Sakai dos Santos ${ }^{1}$, Pedro Teófilo de Sá ${ }^{1}$, Carla Bonomo ${ }^{2}$ \\ ${ }^{1}$ Universidade Oeste Paulista - UNOESTE, curso de Administração, Presidente Prudente, SP. ${ }^{2}$ Universidade Estadual de \\ Londrina - UEL, Londrina, PR. E-mail: alessandra.sakai@hotmail.com
}

\section{RESUMO}

O Administrador desempenha um papel de extrema importância dentro das organizações. Para que a organização funcione é preciso além da atenção com a clientela, o envolvimento da gestão, em busca de resultados positivos. Prezar por cada cliente individualmente, não é mais uma necessidade e sim uma obrigação. As empresas, ao buscarem a finalidade lucrativa devem praticar a Função Social, e analisar a importância e o seu papel na sociedade. Diante disso, este estudo tem como objetivo é o de analisar o papel do administrador para fazer cumprir a função social, atendendo às regras da relação de consumo no fornecimento de produtos ou prestação de serviços. Para tanto, se pesquisará a importância da Função Social na atualidade e a atuação do administrador frente a empresa, a fim de cumprir a Função Social de acordo com o Código de Defesa do Consumidor.

Palavras-chave: Função Social. Código de Defesa do Consumidor. Administrador.

\section{THE ACTING ADMINISTRATOR IN COMPLIANCE FUNCTION OF SOCIAL CONSUMER PROTECTION CODE ON.}

\begin{abstract}
The Administrator plays an extremely important role within organizations. For the organization to work it takes beyond attention to the clientele, the involvement of management in search of positive results. Appreciate by each individual customer, it is no longer a necessity but an obligation. Companies as they seek to profit-making must practice Social Function, and analyze the importance and its role in society. Thus, this study aims is to analyze the manager's role to enforce the social function, meeting the consumption ratio rules in providing products or services. Therefore, it will search the importance of the social function today and the performance of the front administrator the company in order to fulfill the social function in accordance with the Consumer Protection Code.
\end{abstract}

Keywords: Social Function. Consumer Protection Code. Administrator. 


\section{INTRODUÇÃO}

O Administrador de uma organização, independente do tipo de negócio que ela desenvolve, seja produção, comercialização ou prestação de serviços, necessita de muita cautela na atuação de sua profissão. Prestar um atendimento excelente não é mais uma necessidade e sim uma obrigação, visto que o consumidor está cada vez mais exigente na compra de produtos, e o código de Defesa do Consumidor assegura o equilíbrio da relação de consumo nas organizações. Nesse diapasão, independe se está se referindo a serviços a exemplo dos de telecomunicação ou de comercialização de produtos. Além disso, não basta apenas que uma empresa funcione, o Administrador deve fazer cumprir a Função social, para isso o profissional deve tomar as decisões certas visando ao bem comum. Assim, a Função social é primordial para uma empresa, visto que é através dela que a sociedade enxerga com bons olhos a atuação da empresa.

A empresa da atualidade precisa estar atenta para o conjunto de leis e normas que regem os negócios, a economia e o mercado, para que possa, com cautela, exercer o objetivo social da organização.

É preciso não perder o rumo da lucratividade conexa à função social. Nesse ponto, é preciso verificar como se dará a atuação do administrador diante da realidade de mercado, para saber como e quando agir de maneira certeira, de modo a garantir a pretensão econômica.

A qualidade da prestação dos produtos e dos serviços, principalmente naqueles disponibilizados ao atendimento ao cliente precisa, hoje, mais do que qualquer época, ser analisado com cautela em busca de uma pratica gerencial voltada para o respeito da dignidade consumidor.

Por isso, objetivo é o de analisar o papel do administrador para fazer cumprir a função social, atendendo às regras da relação de consumo no fornecimento de produtos ou prestação de serviços. A necessidade da pesquisa se justifica para poder subsidiar e instrumentalizar os administradores para a manutenção da função social diante do Código de Defesa do Consumidor.

\section{METODOLOGIA}

É fundamental a descrição do caminho a ser seguido, para conhecer como foi feita a pesquisa.

Oliveira (1999) afirma que é importante a definição do método a ser utilizado para que a pesquisa tenha um bom andamento e siga caminhos definidos que levem ao alcance dos resultados. Assim sendo, para esta pesquisa foi adotada a abordagem qualitativa, pesquisa bibliográfica e sites públicos. 


\section{RESULTADOS}

Conforme pesquisa realizada identificou-se a necessidade do administrador cumprir a Função Social, demonstrada pelos autores como uma postura aceitável para a sustentabilidade da sociedade, e a preservação da relação de consumo. A prática da Função Social está prevista na Lei das Sociedades Anônimas e precisa ser cumprida. Tal cumprimento depende da atuação do administrador ou fornecedor de produtos ou serviços, que deve estar preocupado com o resultado de suas ações, sem desprezo a Função Social, trazida também pelo Código de Defesa do Consumidor.

\section{DISCUSSÃO}

Adotar uma postura condizente com as leis e normas do Código de Defesa do Consumidor é fundamental para um administrador. A sociedade observa a conduta de uma empresa, e esta por sua vez é reflexo da sua postura. É preciso ser ético em todas as ações de comercialização de produtos ou serviços. Peter e Olson ( 2010, p. 368), afirmam que:

Um estudo propõe que há duas questões que ajudam a identificar se o direcionamento a um grupo de consumidores é ou não antiético. A primeira é até que ponto um produto pode prejudicar os consumidores; a segunda é a vulnerabilidade do grupo. Portanto, a comercialização de produtos prejudiciais em um mercado-alvo vulnerável tende a ser considerada antiética e pode gerar boicotes, propaganda boca a boca negativa e possíveis litígios ou leis desfavoráveis para o setor.

Tal colocação leva a reflexão das ações que são feitas por todos aqueles chamados de fornecedores ${ }^{1}$. Ser ou não ser ético, independente de qual será o ramo, ambas terão reflexos positivos ou negativos no futuro, conforme a escolha. Além disso, os autores salientam que a propaganda boca a boca é uma arma poderosa e pode gerar situações negativas causando assim danos ao setor.

“...o boca a boca na rede está se juntando ao boca a boca tradicional, e talvez até o superando como canal de influência poderoso." (KOTLER; NANCY, 2011, p.327)

Nota-se que, é preciso tomar muito cuidado com os serviços prestados ao consumidor, pois este poderá falar para outros consumidores sobre a má visão que teve em relação a empresa em que adquiriu o produto ou serviço.

Além disso, é importante observar a postura dos administradores (CORDEIRO, 2006):

\footnotetext{
${ }^{1}$ É o fabricante, produtor, importador, comerciante e prestador de serviços, que se dispõe a fornecer bens e serviços a terceiro. 
1. Os gerentes ou administradores da sociedade devem observar:

a) Deveres de cuidado, revelando a disponibilidade, a competência técnica e o conhecimento da atividade da sociedade adequados às suas funções e empregando nesse âmbito a diligência de um gestor criterioso e ordenado; e

b) Deveres de lealdade, no interesse da sociedade, atendendo aos interesses de longo prazo dos sócios e ponderando os interesses dos outros sujeitos relevantes para a sustentabilidade da sociedade, tais como os seus trabalhadores, clientes e credores.

Observa-se que ter fidelidade é um dos requisitos exigidos pela sociedade. É preciso ter atitude e pulso firme para não afetar o próximo. Tanto no interesse dos empresários quanto da sociedade, o administrador necessita cumprir seu papel de acordo com a lei.

O Código de Defesa do Consumidor, no artigo 55, estabelece a obrigação concorrente dos entes públicos na disciplina das normas de proteção de consumo.:

Art. 55. A União, os Estados e o Distrito Federal, em caráter concorrente e nas suas respectivas áreas de atuação administrativa, baixarão normas relativas à produção, industrialização, distribuição e consumo de produtos e serviços.

$\S 1^{\circ}$ A União, os Estados, o Distrito Federal e os Municípios fiscalizarão e controlarão az produção, industrialização, distribuição, a publicidade de produtos e serviços e o mercado de consumo, no interesse da preservação da vida, da saúde, da segurança, da informação e do bem-estar do consumidor, baixando as normas que se fizerem necessárias.

Logo, se observa que o fornecedor de produtos, deve seguir normas e respeita-las conforme estabelecido. Deve-se ter cautela para não prejudicar o consumidor, pois esta é a parte mais vulnerável na relação de consumo, a fim de evitar prejuízos diretos ao consumidor, como também à economia.

Nesse sentido, cabe ainda, trazer a citação do teor do art. 10 do mesmo código, que estabelece a responsabilidade do fornecedor na colocação do produto no mercado de consumo, de modo a não causar qualquer nocividade ao consumidor.

Art.10. O fornecedor não poderá colocar no mercado de consumo produto ou serviço que sabe ou deveria saber apresentar alto grau de nocividade ou periculosidade à saúde ou segurança.

$\S 1^{\circ} \mathrm{O}$ fornecedor de produtos e serviços que, posteriormente à sua introdução no mercado de consumo, tiver conhecimento da periculosidade que apresentem, deverá comunicar o fato imediatamente ás autoridades competentes e aos consumidores, mediante anúncios publicitários.

Nota-se que as ações do fornecedor são vigiadas, indiretamente, pelo Código Consumerista. Com isto, o administrador ao executar os objetivos da empresa, observando a 
função social, deve estar atento para à qualidade do produto disponibilizado, para que a organização não tenha que ser responsabilizada por eventuais danos causados ao consumidor. Vale lembrar que o Código tem a função de equilibrar a relação de consumo em busca de uma relação de consumo sadia, de modo a atender as necessidades sociais, respaldadas na legalidade.

O século XXI exige das empresas que o administrador tenha uma postura estratégica e eficiente, que gere maior satisfação ao consumidor. Neste primeiro momento é fundamental conhecer a Função Social voltada para a atuação do Administrador ou fornecedor. Os artigos 116, parágrafo único e 154, da Lei das Sociedades Anônimas², abaixo transcrito, trazem que:

Art. 116. (omisso)

Parágrafo único. $\mathrm{O}$ acionista controlador deve usar o poder com o fim de fazer a companhia realizar o seu objeto e cumprir sua função social, e tem deveres e responsabilidades para com os demais acionistas da empresa, os que nela trabalham e para com a comunidade em que atua, cujos direitos e interesses deve lealmente respeitar e atender.

Art. 154. O administrador deve exercer as atribuições que a lei e o estatuto Ihe conferem para lograr os fins e no interesse da companhia, satisfeitas as exigências do bem público e da função social da empresa.

Segundo esta Lei, a Função Social exerce um papel de grande importância nas relações empresariais, pois toda empresa deve cumpri-la. Portanto, tal função constitui uma obrigação que todos devem ter. Exercer tal função é se preocupar com a sociedade, pensar como as decisões praticadas pelo administrador podem afetar a coletividade ou o ambiente em que está inserido. Assim, a finalidade da empresa não é apenas almejar o lucro, mas sim, atuar voltada para o atingimento e respeito ao bem comum, fato que privilegia não só as partes, como o consumidor e o fornecedor.

“A função social da empresa representa, portanto, um conjunto de fenômenos importantes para coletividade e é indispensável para a satisfação dos interesses inerentes à atividade econômica". (ALMEIDA, 2003, p. 141)

Observa-se que função social é indispensável para todos os fornecedores, já que precisam vender seus produtos e serviços para gerar renda, já que os consumidores estão atentos aos atos dos fornecedores e se cumprem ou não a função social.

Almeida (2003, p. 151) ainda acrescenta que "A interpretação em torno da função social da empresa representa um conjunto de fenômenos importantes para a sociedade e é indispensável para a satisfação dos interesses coletivos."

\footnotetext{
${ }^{2}$ Lei n ${ }^{\circ} 6.404 / 76$
} 
Sendo assim, entende-se que, a função social, para ambas as partes, se torna relevante, por isso cabe às empresas adotarem uma postura de cuidado e zelo que leve a pratica da função social. Pela ótica empresarial, projeta o respeito aos ditames legais, já pela ótica do consumidor denota a satisfação dos seus interesses com respeito aos seus direitos e, consequentemente, à sua dignidade.

Cabe aqui outro olhar relacionado ao exercício da Função social, lembrando que ela surgiu e se desenvolveu voltada para a propriedade rural, e depois foi se estendendo para as demais relações negociais, especificamente na relação de consumo, e nas relações contratuais. Vale observar o teor do artigo 9o da Lei 8.629/93, (BRASIL, 1993):

Art. 9o A função social é cumprida quando a propriedade rural atende, simultaneamente, segundo graus e critérios estabelecidos nesta lei, os seguintes requisitos:

I - aproveitamento racional e adequado;

II - utilização adequada dos recursos naturais disponíveis e preservação do meio ambiente;

Diante desse contexto geral e do nascimento da função social, esta deve estar presente não apenas nas relações comerciais, mas também no exercício da propriedade da pessoa com a área rural, já que esta pode ser usada para a produção, caso em que a função social está voltada para o respeito à regras ambientais.

Por isso, quando se fala em produção, o administrador, que representa o fornecedor ou proprietário deve agir com ética e com índole, a fim de adotar ações sustentavelmente corretas.

Uma empresa ou associação deve praticar a função social, e ainda Zanoti $(2006$, p. 99) faz a seguinte observação:

[...] somente será considerada uma empresa socialmente responsável se, além de cumprir plenamente a sua função social, proporcionar, por mera liberalidade, porém, sem imposição coercitiva, e de forma regular, perene, uma gama de benefícios sociais para a sociedade, com o intuito de se promover a valorização da dignidade da pessoa humana, comprometendo-se, inclusive, com a eficácia da aplicação desses recursos financeiros e/ou materiais, bem como com os resultados sociais que se pretende atingir.

O autor aqui traz, em poucas palavras, o foco desta pesquisa, corroborado com a afirmação de que a empresa não deve ter ações coercitivas quando diz respeito à função social, mas sim deve visar a valorização do ser humano em seus atos praticados.

Para Zanoti (2006, p. 206) a questão da função social está conexa com a noção de bem comum. 
A função social se constitui na essência do bem comum. É por isso que ela deve prevalecer no conteúdo das normas jurídicas, vez que estas têm o condão de regular as relações em sociedade, de forma que os interesses coletivos tenham predomínio sobre os de natureza individuais.

Então, é possível verificar que a função social dará dá a devida relevância à sociedade, e isto acontecerá quando o administrador com a sua postura proativa, permanecer alerta e com respeito as normas jurídicas, que devem ser cumpridas por todos no meio social.

\section{CONCLUSÃO}

As ações praticadas pelas empresas diante da sociedade moderna devem ser versadas na busca da pratica da função social. Eis o grande desafio do administrador diante da complexidade das relações existentes na sociedade. Por isso as suas ações devem ser pautadas no respeito à norma em busca do atingimento dos objetivos empresariais, sem, no entanto, se esquecer da sustentabilidade e da sociedade.

Hodiernamente, o Código de Defesa do Consumidor cuida exclusivamente do consumidor e da relação de consumo, protegendo a parte vulnerável e hipossuficiente desta relação. Por isso, o fornecedor deve ter cuidado com a prática de qualquer ação relacionada com a comercialização de produtos ou prestação de serviços. Obedecer ao Código de Defesa do Consumidor evitará diversos problemas e punições. Então, a prática de ações que respeitem e a contemplem a função social caracteriza um administrador com atitude e conduta totalmente voltada para o bem comum e social.

Tal atitude deverá ser seleta, proativa, com sabedoria e conhecimento para não afetar a parte interessada, de modo que possa ser atendida a função social da empresa, para harmonicamente reger a relação de consumo.

Diante das evidências literárias, a postura do administrador deve ser a de praticar e respeitar a função social em todo o momento, ou seja, deve ter a preocupação de saber se as suas ações estão corretas diante do contexto legal e social. Então, o fornecedor, representado pelo o administrador não deverá visar o lucro a todo custo, mas sim se preocupar em colher benefícios de modo recíproco. Por isso, pode-se afirmar que a função social para uma empresa é essencial na garantia da sustentabilidade da relação de consumo.

\section{REFERÊNCIAS}


ALMEIDA, M. C. A função social da empresa na sociedade contemporânea: perspectivas e prospectivas. Argumentum, Marília, v 3, n 3, p. 141 a 151, 2003. Disponível emhttp://www.unimar.br/biblioteca/publicacoes/pos/Direito vol 03.pdf Acesso em: 13 ago. 2015.

BRASIL. Presidência da República Casa Civil. LEI №. 6.404, DE 15 DE DEZEMBRO DE 1976. Dispõe sobre Dispõe sobre as Sociedades por Ações. Diário Oficial da União, Brasilia, DF, 15 dez. 1976. Disponível em: <http://www.planalto.gov.br/ccivil 03/leis/L6404consol.htm>. Acesso em: 10 ago. de 2015.

BRASIL. Presidência da República Casa Civil. LEI №. 8.078, DE 11 DE SETEMBRO DE 1990. Dispõe sobre a proteção do consumidor e dá outras providências. Disponível em: < http://www.planalto.gov.br/ccivil 03/Leis/L8078.htm>. Acesso em: 10 ago. de 2015.

BRASIL, 1993. Lei 8.629 de 25 de fevereiro de 1993. Dispõe sobre a regulamentação dos dispositivos constitucionais relativos à reforma agrária, previstos no Capítulo III, Título VII, da Constituição Federal. Diário oficial da União, Brasília, 26 fev.1993.Disponível em:< http://www.planalto.gov.br/CCivil 03/Leis/L8629.htm> Acesso em: 15 ago. 2015.

CORDEIRO, A. M. Os deveres fundamentais dos administradores das sociedades. Doutrina, v. 2, ano 66, set, 2006. Disponível em: http://www.oa.pt/Conteudos/Artigos/detalhe artigo.aspx?idc=1\&idsc=50879\&ida=50925> Acesso em: 24 mai. 2015.

KOTLER, P.; LEE, N. R. Marketing social: influenciando comportamentos para o bem. São Paulo: bookman, 2011.

LEITE, R.B. Introdução ao Direito do Consumidor. São Paulo: LTR, 2002.

MARQUES, C. L. Contratos no Código de Defesa do Consumidor. O novo regime das relações contratuais. 5a ed. Ver. Atual. E ampl. São Paulo: RT, 2005.

OLIVEIRA, S. L. Tratado de metodologia científica: Projetos de pesquisas, TGI, TCC, Monografias, Dissertações e Teses. 2.ed. São Paulo: Pioneira, 1999.PETER, J. P.; OLSON, J. C. Comportamento do Consumidor e Estratégia de Marketing.8a edição. Porto Alegre: AMGH, 2010.

TELES, G. F. S. A função social da empresa. Disponível em: < http://blog.newtonpaiva.br/direito/wp-content/uploads/2012/08/PDF-D13-03.pdf> Acesso em: 08 ago. 2014.

ZANOTI, L. A. R. A função social da empresa como forma de valorização da dignidade da pessoa humana. 2006. 241 f. Dissertação (Mestrado em Direito) - Universidade de Marília, Marília. 